Review

\title{
Covalent immobilization of antimicrobial peptides (AMPs) onto biomaterial surfaces
}

\author{
Fabíola Costa ${ }^{\mathrm{a}}$, Isabel F. Carvalho ${ }^{\mathrm{b}}$, Ronald C. Montelaro ${ }^{\mathrm{c}}$, P. Gomes ${ }^{\mathrm{d}}$, M. Cristina L. Martins ${ }^{\mathrm{a}, *}$ \\ a INEB - Instituto de Engenharia Biomédica, Divisão de Biomateriais, Universidade do Porto, Rua do Campo Alegre 823, 4150-180 Porto, Portugal \\ ${ }^{\mathrm{b}}$ IBMC - Instituto Biologia Celular e Molecular, Universidade do Porto, Rua do Campo Alegre 823, 4150-180 Porto, Portugal \\ ${ }^{\mathrm{c}}$ Microbiology and Molecular Genetics, University of Pittsburgh School of Medicine, Pittsburgh, PA, USA \\ ${ }^{\mathrm{d}}$ CIQ-UP, Departamento de Química e Bioquímica, Faculdade de Ciências, Universidade do Porto, Rua do Campo Alegre 687, 4169-007 Porto, Portugal
}

\section{A R T I C L E I N F O}

\section{Article history:}

Received 6 July 2010

Received in revised form 5 October 2010

Accepted 1 November 2010

Available online 5 November 2010

\section{Keywords:}

Antimicrobial peptides

Bacterial adhesion

Biofilms

Surface functionalization

Nanostructured surfaces

\begin{abstract}
A B S T R A C T
Bacterial adhesion to biomaterials remains a major problem in the medical devices field. Antimicrobial peptides (AMPs) are well-known components of the innate immune system that can be applied to overcome biofilm-associated infections. Their relevance has been increasing as a practical alternative to conventional antibiotics, which are declining in effectiveness. The recent interest focused on these peptides can be explained by a group of special features, including a wide spectrum of activity, high efficacy at very low concentrations, target specificity, anti-endotoxin activity, synergistic action with classical antibiotics, and low propensity for developing resistance. Therefore, the development of an antimicrobial coating with such properties would be worthwhile. The immobilization of AMPs onto a biomaterial surface has further advantages as it also helps to circumvent AMPs' potential limitations, such as short half-life and cytotoxicity associated with higher concentrations of soluble peptides. The studies discussed in the current review report on the impact of covalent immobilization of AMPs onto surfaces through different chemical coupling strategies, length of spacers, and peptide orientation and concentration. The overall results suggest that immobilized AMPs may be effective in the prevention of biofilm formation by reduction of microorganism survival post-contact with the coated biomaterial. Minimal cytotoxicity and longterm stability profiles were obtained by optimizing immobilization parameters, indicating a promising potential for the use of immobilized AMPs in clinical applications. On the other hand, the effects of tethering on mechanisms of action of AMPs have not yet been fully elucidated. Therefore, further studies are recommended to explore the real potential of immobilized AMPs in health applications as antimicrobial coatings of medical devices.
\end{abstract}

() 2010 Acta Materialia Inc. Published by Elsevier Ltd. All rights reserved.

\section{Introduction}

The use of biomaterial implants and medical devices such as catheters, heart valves, stents, shunts, arthoprostheses and fracture fixation devices is an increasingly common and often life-saving procedure. Although infection incidence has been reduced by aseptic surgical techniques and prophylactic systemic antibiotic therapy, bacterial colonization of medical devices or implants still represents a serious hazard [1-3]. Mortality attributable to such infections is highest among patients with cardiovascular implants, particularly prosthetic heart valves and aortic grafts. However, infections associated with orthopaedic devices often result in serious disabilities [4]. These infections may cause implant failure, complex revision processes and implant removal, all leading to patient suffering, prolonged hospitalization and even death [5].

Implant-associated infections are classified in three ways: superficial immediate infections, deep immediate infections and

\footnotetext{
* Corresponding author. Tel.: +351 226074982.

E-mail address: cmartins@ineb.up.pt (M. Cristina L. Martins).
}

deep late infections. Superficial immediate infections are caused by bacteria that normally populate the skin and start to colonize the medical device (e.g. infected sutures). Deep immediate infections become apparent shortly after invasive surgeries and may be due to inadvertent relocation of skin bacteria into the body, i.e. non-sterile implantation procedures. Finally, deep late infections appear months or years after surgery and may be a delayed display of contamination that was seeded during surgery or resulted from bacteria that migrated from another anatomic site [6].

Implant surface susceptibility to infection is dependent on the immune system performance and on the activity and virulence of the involved microorganisms [2,7]. Immune system performance can be compromised by direct surgical trauma, implant presence, low availability of blood vessels in the implant vicinity and inflammatory escalation, frequently resulting in peri-implant tissue damage. The activity and virulence of microorganisms are correlated with their capacity for biofilm formation [8]. Biofilms can colonize almost every kind of material (metals, ceramics and polymers) and therefore medical devices [9]. Biofilms are a differentiated, highdensity population of microorganisms that are surrounded by a 
three-dimensional, well-organized exopolymeric matrix composed of polysaccharides, proteins, nucleic acids and lipids produced simultaneously by the microorganisms in the biofilm [3] and by proximal host cells $[10,11]$. This biofilm matrix is characterized by its resistance to stressful environmental conditions such as UV radiation, $\mathrm{pH}$ variation, osmotic shock, desiccation and flow conditions, and additionally by prevention of the entrance of antibiotics and biocidal substances [9]. Furthermore, the biofilm structure facilitates horizontal gene transfer between resistant and non-resistant microbial strains [9]. The overall result is an antibiotic resistance that is typically $10-1000$ higher in biofilms than in the planktonic form of the same bacterial species $[9,12,13]$. Moreover recent research data have demonstrated that sub-therapeutic doses of both classical and recent antibiotics may induce specific gene expression, resulting in the paradoxical effect of exarcebating biofilm formation [14-17].

Biofilm establishment results from a specific sequence of events: microbial adherence, microcolony formation and proliferation, matrix production, biofilm maturation and, finally, cell detachment with propagation of infection $[2,3]$. Therefore, biofilms may represent reservoirs for the development of pathogenic infections $[2,3]$. When a biomaterial is implanted, a conditioning layer primarily composed of proteins (fibronectin, vitronectin, fibrinogen, albumin and immunoglobulins) adheres to its surface, favouring surfacemicroorganism interactions $[5,13]$. The interaction between bacteria and surface proteins results initially from weak attraction forces such as Van der Waals and electrostatic charges, which are later reinforced by specific interactions involving bacterial adhesion proteins [9]. Further, cell adhesion is facilitated by bacterial signalling and matrix production, yielding a mature biofilm $[2,13]$. After formation, a biofilm cannot be easily eliminated by standard clinical procedures, and the infection often can only be eradicated by the removal of the infected implant. In order to solve this problem, research has been conducted on the development of antimicrobial surface coatings that can prevent the initial bacterial colonization and/or actively reduce bacterial titres, minimizing the potential for biofilm formation $[2,10]$.

\section{Antimicrobial coatings}

In order to avoid implant-associated infections, several strategies have been reported with the aim of creating antimicrobial surfaces, such as the development of (i) non-fouling surfaces (surfaces that avoid protein adsorption and cell adhesion) [1,18-20], (ii) surfaces previously colonized with non-pathogenic bacteria [9], (iii) surfaces combined with biocidal substances [21-23] and (iv) surfaces combined with antibiotics [24-26].

The physicochemical properties of the implant surface, such as surface roughness energy and potential, are fundamental issues in the initial adhesion and subsequent growth of bacteria. Non-fouling surfaces combine one or more approaches in order to influence the amount and/or conformation of adsorbed proteins, preventing bacterial adhesion and biofilm formation. Some examples are UV radiation of titanium surfaces to augment wettability [27], use of anti-adherent agents bearing negative charges [28], polymer coatings such as poly(ethylene glycol) (PEG), poly(hydroxyethylmethacrylate) (PHEMA) [18,29], poly(methacrylic acid) [30], polyurethanes [31] or even bioactive polymers such as chitosan, which possess the ability to inhibit bacterial adhesion and/or to kill adherent bacteria [32]. Unfortunately, the effectiveness of non-fouling coatings for reducing bacterial adhesion is limited and varies greatly depending on bacterial species.

Another approach involves the simultaneous use of an antimicrobial agent and a non-pathogenic bacterial coating layer. The non-pathogenic bacteria, resistant to a specific antimicrobial is used to populate the ecological space, preventing adherence of pathogenic bacteria to the surface [9].

Surfaces combined with antibiotics or other biocidal substances have the advantage of delivering drugs directly to the implant site, resulting in locally high drug doses without exceeding the systemic toxicity level of the drug, thus preventing harmful side effects [3]. Several antimicrobial surfaces have been described in the literature, including non-antibiotic antimicrobial agents such as silver, salicylic acid, quaternary ammonium compounds, phenol derivatives, chlorhexidine and nitric oxide [3,5,13,33]. However, many of these compounds are associated with anaphylaxis, cytotoxicity or low efficiency $[5,13]$. These limiting aspects prompt the use of true antibiotics such as vancomycin, tobramycin, cefalozin, teicoplanin, carbenicillin, amoxicillin, penicillin, ampicillin and gentamicin [3,34-37], through two different strategies: substance-releasing coating and substance covalent immobilization. The release strategy offers the potential for extended activity, but has to date failed to achieve delivery of a sustained and effective dosage over a relatively prolonged period of time. To address this issue, there has been an increased interest in covalent attachment of drugs to the implant surface to achieve long-lasting antibacterial activity. For example, vancomycin has been successfully attached to titanium and proven to be bactericidal to Staphylococcus aureus and Staphylococcus epidermidis [5,7]. In addition, Aumsuwan et al. $[34,37]$ reported the covalent attachment of penicillin and ampicillin to expanded polytetrafluoroethylene (ePTFE). When these drugs were immobilized through a PEG-spacer, the surfaces displayed high antimicrobial efficiency among their spectrum of activity, indicating that antibiotic mobility is essential to activity. The advantages of covalent attachment to the implant surface are long-lasting antimicrobial activity, low incidence of side effects and non-accumulation in tissues (brain, liver and spleen) [5]. However, the effectiveness of coatings with classical antibiotics is strongly dependent on the spectrum of activity of the chosen drug, and the possibility of development of antimicrobial resistance in a relatively short time period [38]. Therefore, alternative answers must be developed. There is a clear need for a broad-spectrum antimicrobial that prevents colonization of biomaterials, minimizes the development of bacterial resistance, displays long-term stability, even through the sterilization process, and has a low cytotoxic profile. Antimicrobial peptides have the potential to meet these criteria [39-42] and therefore represent a promise for the new generation of antimicrobial surfaces.

\section{Antimicrobial peptides}

In the past 50 years, resistance to new antibiotics has appeared in microbial populations within a few years of the introduction of a new therapeutic drug [38]. The decline in the effectiveness of current therapies has led to a search for new kinds of agents, including antibiotics based on antimicrobial peptides (AMPs), which are part of the innate immune system of all multicellular organisms [39-43]. So far, more than 750 different AMPs have been isolated from a wide variety of animals, plants, bacteria, fungi and viruses $[39-42,44]$. The AMPs comprise a chemically and structurally heterogeneous family. Nevertheless, three characteristics that are shared by almost all known AMPs can be distinguished: (i) small size (10-25 amino acids), with molecular weights (MW) between 1 and $5 \mathrm{kDa}$; (ii) highly cationic character, though with large variations in the net positive charge; (iii) tendency to adopt amphipathic structures, i.e. structures with separate hydrophobic and hydrophilic domains, in non-polar media. Because of these physicochemical characteristics, AMPs have the tendency to associate with negatively charged microbial surfaces and membranes [45]. These peptides offer several attractive advantages: they exhibit 
bactericidal, fungicidal, viricidal and tumoricidal properties, they act at a very low concentration, and they are less likely to promote bacterial resistance. These properties make AMPs promising candidates for therapeutic drugs [44]. Unlike conventional antibiotics such as penicillin, which microbes readily deceive, acquisition of resistance by a sensitive microbial strain against AMPs is less probable. Because the target of AMPs is the bacterial membrane, a microorganism would have to redesign its membrane, changing the composition and/or organization of its lipids, which represent an expensive solution for most microbial species.

However, some resistance mechanisms have been reported in Gram-positive and Gram-negative bacteria. For instance, some Gram-positive bacteria (e.g. S. epidermidis, S. aureus) can express an AMP sensor system that has been proposed to regulate selected resistance genes when the bacteria come into contact with AMPs [46-48]. These resistance genes include dlt-operon, which is responsible for D-alanylation of teichoic acid; mprF, which mediates the incorporation of lysyl-phosphatidylglycerol in the cytoplasmic membrane (both of these genes decrease the negative net charge of the cell envelope); and the vraFG genes of a transport system $[46,47,49-51]$. Other reported resistance mechanisms include protease inhibitors, such $S$. aureus IsdA surface protein [52], and biofilm stabilizers such exopolysaccharide intercellular adhesin (PIA) [53]. Nevertheless, bacterial resistance mechanisms to AMPs differ with regard to efficiency, specificity and distribution among species [46], and natural AMPs have evolved to avoid some of these resistance mechanisms. Moreover, synthetic AMPs can be rationally engineered to circumvent specific bacterial resistance mechanisms based on the specific application (target bacteria, environment, etc.).

Most peptides are created from nondescript sequences of amino acids lacking unique motifs that could serve as the recognition site of a protease required for selective destruction of the antibiotic in the presence of cellular protein constituents [54]. Furthermore, some cationic peptides bind to lipopolysaccharide (LPS) and lipoteichoic acid (LTA) with high affinity (competitively displacing membrane-stabilizing bivalent cations $\mathrm{Ca}^{2+}$ or $\mathrm{Mg}^{2+}$ ), disrupting these sites and leading to enhanced uptake of cationic peptides across the outer membrane. Disruption of outer membranes can also lead to promotion of uptake of conventional antibiotics across the outer membrane, leading to an "enhancement" effect. This selfpromoted uptake process is responsible for two additional advantages: anti-endotoxin activity, in contrast to other antibiotics, which induce endotoxinaemia, and "enhancer" activity (i.e. synergy with classical antibiotics) $[45,55,56]$. The more resistant an isolate is to a given antibiotic, the more profound is the "enhancement" effect by an appropriate cationic peptide. Thus cationic peptides also have the ability to serve as anti-resistance compounds $[45,55]$.

The properties of natural AMPs have prompted research towards de novo AMPs, i.e. fully synthetic peptides. These are distinct from those in nature, with simpler but rationally engineered composition, obtained by varying the amino acid content and sequence and overall peptide length to achieve enhanced activity and very low cytotoxic properties [57]. For example, Mietzner and co-workers [58-61] have developed a series of de novo peptides based on structure-function properties observed in natural AMPs. They engineered the peptide composition to achieve enhanced potency, selectivity and stability. They performed extensive in vitro and in vivo (intravenous murine infection model and intraperitoneal mouse infection model) studies in order to evaluate the antimicrobial activity (against Pseudomonas aeruginosa, S. aureus, Streptococcus gordonii, Fusobacterium nucleatum and Porphyromonas gingivalis), cytotoxicity (towards red blood cells, white blood cells, human skin fibroblasts), and salt resistance (towards $\mathrm{NaCl}, \mathrm{Mg}^{2+}$ and $\mathrm{Ca}^{2+}$ ). The engineered peptide derivative WLBU2 (RRWVRRVRRWVRRVVRVV
RRWVRR) was identified as a promising prophylactic and therapeutic molecule. The in vitro studies revealed good selectivity, and potency at physiological conditions (salt resistance), which was reinforced by in vivo efficacy in the intravenous and intraperitoneal $P$. aeruginosa infection models.

Finally, the potential of future AMP-based drugs is underlined by the number of clinical trials with various AMP species for treatment of skin and soft tissue infections, oral mucositis and paediatric sepsis $[44,62,63]$.

\subsection{Mode of antibacterial action}

AMPs target the fundamental difference in the membrane structures of microorganisms and multicellular animals. Bacterial membranes are organized in such a way that the outermost leaflet of the bilayer is heavily occupied by lipids with negatively charged phospholipid headgroups. In contrast, the outer leaflet of the membranes of plants and animals is composed principally of lipids with no net charge. Here most of the lipids with negatively charged headgroups are segregated into the inner leaflet, facing the cytoplasm [54].

Although the exact mechanism of action of AMPs remains a matter of controversy, there is a consensus that the following sequence occurs: (i) cationic, i.e. positively charged, peptides are electrostatically attracted to the negatively charged microbial cell membranes, and (ii) upon binding to the phospholipid membrane, the AMP adopts an amphipathic structure, adapting to the specific conditions at the membrane-water interface. Most AMPs only assume their amphipathic structure upon interaction with the membrane, as it is not the most favoured structure in water. This interaction is generally believed to lead to a lethal increase in the permeability of the cell membrane [45]. How this interaction ends in fatal outcome still remains to be determined. Many hypotheses have been presented, which include: fatal depolarization of the normally energized bacterial membrane; creation of physical holes resulting in leakage of cellular contents; activation of deadly processes such as induction of hydrolases that degrade the cell wall; alteration of the usual distribution of lipids between the leaflets of the bilayer that results in disturbance of membrane functions; and damage to the critical intracellular targets after internalization of the peptide [54]. Recently, it has been shown that peptide reorientation together with membrane destabilization happens after a certain peptide threshold concentration is achieved. This can be ascribed to a first step of membrane surface coverage by the AMP until charge neutralization is reached. Thereafter, peptide orientation changes from parallel to perpendicular to the membrane surface, followed by pore formation and eventually membrane disruption [64-66].

Based on the available data, three models explaining the mode of action of AMPs have been proposed (Fig. 1).

(i) The carpet model: After the microbial cell membrane is fully covered by a carpet-like cluster of peptides, a saturation point is reached that results in extensive wormhole formation, causing the abrupt lysis of the microbial cell. Cell lysis is believed to result as the lipid layer bends back on itself, with lateral expansions in the polar head-group region, providing the gaps that will be filled up by individual peptide molecules.

(ii) The toroidal pore model: After binding to the phospholipid head groups, the peptides insert into the membrane and then cluster into unstructured bundles that span the membrane. These bundles, in association with water molecules, are believed to create channels responsible for leakage of ions and possibly larger molecules throughout the membrane. This last model differs from the other two in that only 

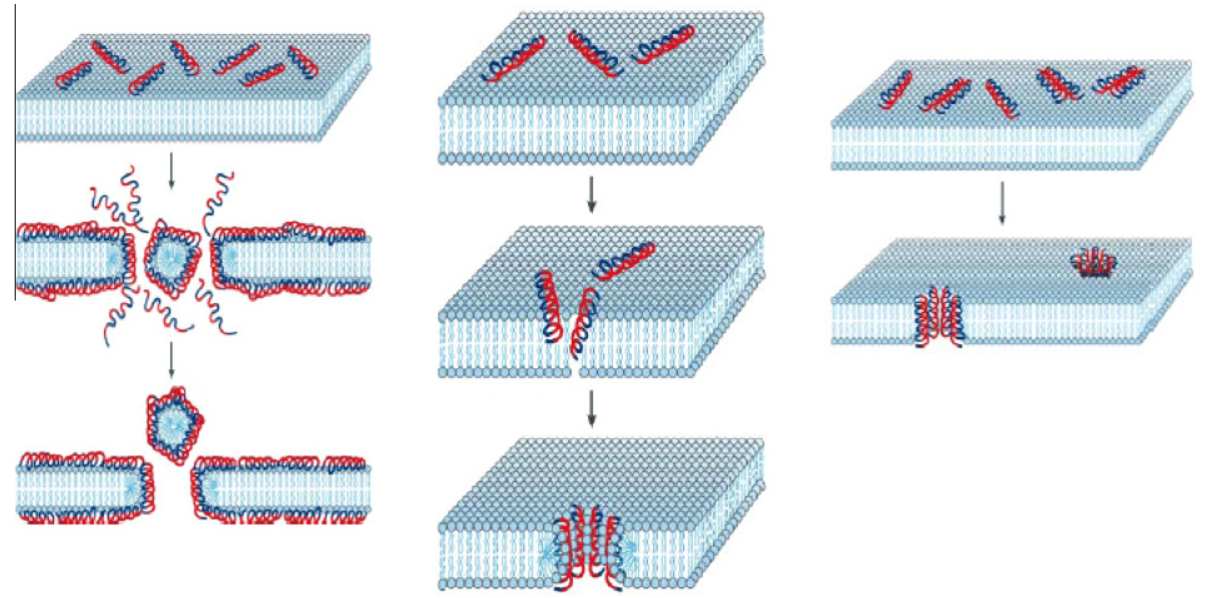

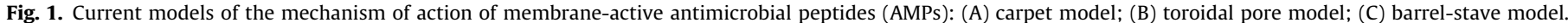
Adapted with permission from Ref. [64].

short-lived transmembrane clusters of an undefined nature are formed, which allows the peptides to cross the membrane without causing significant membrane depolarization. Once inside, the peptides home on their intracellular targets to exert their killing activities [45].

(iii) The barrel-stave model: After initial electrostatic binding to the outer leaflet of the bacterial membrane, $\alpha$-helical amphipathic peptides group together into barrel-like bundles that line amphipathic transmembrane pores. The non-polar side chains associate with the hydrophobic fatty acid tails at the inside of the phospholipid bilayer, and the hydrophilic side-chains are oriented inward into the water-filled pore.

Taking into consideration the proposed theories for soluble AMPs, one could expect that immobilized AMPs would lose their antimicrobial activity completely or to a large extent. However, the research reviewed herein proves differently, and even provides some insights into the specific mechanisms underlying this activity. Haynie et al. [67] was able to demonstrate that immobilized magainin that is attached through very short linkers ( 2 or 6 carbon atoms) displays antimicrobial activity, meaning that outer membrane interaction by magainin is sufficient for lethal activity. Humblot et al. [68] reported that the immobilized AMPs had a bacteriostatic rather that bactericidal effect, perhaps due to the low peptide concentration or short contact time. Other research has performed the immobilization through long linkers in an attempt to permit sufficient flexibility to penetrate target cell membranes $[1,69,70]$, as the directly attached AMPs lost their antimicrobial activity. Hilpert et al. [71], in their screening and characterization of surface-tethered cationic peptides studies, reported that the immobilization of peptides to a surface should result in constraints on the peptide mobility and on the capacity of peptides to enter or even transpose the cellular membranes. Scanning electron microscopy (SEM), ATP release and depolarization assays performed with short peptides indicated that, although their length was insufficient to stretch across the membrane, the immobilized peptides could destabilize the cell membrane. The high local concentration of immobilized peptides was presumed to lead to the displacement of positively charged counterions attached to the outer surface layers. This could promote a dramatic change in bacterial surface electrostatics, which could trigger the activation of autolytic enzymes or the disruption of the ionic balance of more internal layers. Hilpert et al. [71] also demonstrated that hydrophobic residues at the exposed end of immobilized AMPs can have a major influence on the antimicrobial activity. They suggested that these residues are responsible for the triggering connection between AMPs and the bacteria cell wall.

\section{Covalent immobilization of an antimicrobial peptide}

The toxicity sometimes associated with AMPs is usually related to the high concentrations used to compensate for the relatively short half-life of AMPs due to a rapid protease digestion [67], or to peptide aggregation [11]. These characteristics have limited the use of AMPs in applications that require systemic distribution of the antimicrobial. However, AMPs are designed to work at local surfaces in most of their natural applications. Thus, stable immobilization of AMPs onto a biomaterial could be the pathway to overcome these difficulties [72]. Covalent immobilization of AMP can increase their long-term stability while decreasing their toxicity, as compared to incorporation approaches on leach- or releasebased systems $[11,35,36,69,72-75]$. Furthermore, the proper orientation of the peptide may result in enhanced activity [34]. Towards this goal, the effect of AMP chemical immobilization on antimicrobial activity has been studied by several investigators [3,4,6, 25-27,29,48,49,71] (Table 1). In the current review, different AMP surface covalent immobilization strategies are discussed, focusing on the importance of solid supports and chemical coupling strategies, spacer specificities (type, length and flexibility), surface density and exposure/orientation as determinants of immobilized peptide biocidal and cytotoxic activity. As summarized in Table 1, the various studies of immobilized AMPs differ in important aspects, including the immobilization method applied, the peptide sequence, mode of action of the AMPs used, and the bacteria tested. These experimental variations make it difficult to achieve a straightforward comparison. Nevertheless, important lessons can be derived from these diverse studies.

In 1995, Haynie et al. [67] demonstrated that some AMPs (natural occurring magainin 2 and several idealized synthetic amphipathic peptides) immobilized onto a polyamide resin (pepsin $\mathrm{K}$ ) retained lethal activity against several Gram-positive and Gramnegative bacteria. As already mentioned, these results demonstrated that the interaction of magainin with the outer membrane of the bacteria is sufficient for their lethal activity, since the potential peptide penetration depth is very low due to the short spacer (short 2 or 6 carbon chain linkers) used.

Willcox et al. [11] compared the antimicrobial activity of the synthetic peptide melimine that was adsorbed or covalently immobilized onto commercial contact lenses (Etafilcon A). Covalent 
Table 1

Overview of the reported AMP immobilization strategies.

\begin{tabular}{|c|c|c|c|c|}
\hline & AMP & Substrate & AMP immobilization strategy & Microorganisms assessed \\
\hline [67] & $\begin{array}{l}\text { Magainin } 2 \text { and } \\
\text { Related } \\
\text { synthetic } \\
\text { amphiphilic } \\
\text { peptides }\end{array}$ & Polyamide resin (pepsin $\mathrm{K}$ ) & $\begin{array}{l}\text { Directly synthesized on polyamide resin, after } \\
\text { immobilization through their } C \text {-terminal amino acids } \\
\text { - AMP orientation was controlled } \\
\text { - Short spacer, with } 2 \text { - or } 6 \text {-carbon chains, was used } \\
\text { - Stability to heat was studied } \\
\text { - no AMP release was observed }\end{array}$ & $\begin{array}{l}\text { Escherichia coli ATCC 35695; and ATCC } \\
25922 \text {, Staphylococcus aureus ATCC } \\
25923 \text { and ATCC 6538, Klebsiella } \\
\text { pneumoniae ATCC 4352, Bacillus subtilis } \\
\text { ATCC 6051, Candida albicans ATCC } \\
\text { 10231, Aspergillus niger ATCC 6275, and } \\
\text { Pseudomonas aeruginosa ATCC } 27853 \text {. }\end{array}$ \\
\hline [1] & Magainin I & $\begin{array}{l}\text { Non-fouling copolymer brushes based } \\
\text { on different percentages of:2-( } 2- \\
\text { methoxyethoxy)ethyl methacrylate } \\
\left(\mathrm{MEO}_{2} \mathrm{MA}\right) / \text { hydroxyl-terminated } \\
\text { oligo(ethylene glycol) methacrylate } \\
\text { (HOEGMA) }\end{array}$ & $\begin{array}{l}\text { Peptide immobilized by its } C \text {-terminal amino acid } \\
\text { The process consisted of a previous incorporation of a } \\
\text { cysteine residue on the } C \text {-terminal of magainin, to be } \\
\text { reacted with the polymeric brushes via PMPI ( } \mathrm{N}-(\mathrm{p} \text { - } \\
\text { maleimidophenyl)isocyanate) } \\
\text { - AMP orientation was controlled } \\
\text { - Brushes were used as spacers } \\
\text { - Different AMPs densities was tested }\end{array}$ & Listeria ivanovii, Bacillus cereus \\
\hline [68] & Magainin I & $\begin{array}{l}\text { Mixed } \mathrm{OH} / \mathrm{COOH} \text {-terminated self- } \\
\text { assembled monolayers (SAMs) }\end{array}$ & $\begin{array}{l}\text { Immobilization by the free AMP amines after activation } \\
\text { of the COOH groups of the SAM with NHS/EDC } \\
\text { - AMP orientation was not controlled } \\
\text { - No spacers } \\
\text { - No AMP release was observed }\end{array}$ & $\begin{array}{l}\text { L. ivanovii, Enterococcus faecalis and } S \text {. } \\
\text { aureus }\end{array}$ \\
\hline [69] & $\begin{array}{l}\text { Magainin- } \\
\text { derived MK5E } \\
\text { and KLAL }\end{array}$ & $\begin{array}{l}\text { PEGylated TentaGel S, HypoGel } 400 \\
\text { and HypoGel } 200 \text { resin beads }\end{array}$ & $\begin{array}{l}\text { C-terminally immobilized peptides were achieved by } \\
\text { standard solid-phase peptide synthesis and Fmoc (9- } \\
\text { fluorenylmethoxycarbonyl)-chemistry } \\
\text { N-terminal and side-chain immobilization were } \\
\text { achieved by thioalkylation and oxime formation } \\
\text { - AMP orientation was controlled } \\
\text { - Different AMPs densities were tested } \\
\text { - Effect of PEGylated spacers was tested } \\
\text { - The haemolytic effect was assayed }\end{array}$ & $\begin{array}{l}\text { E. coli strain DH5 } \alpha, \text { B. subtilis strain DSM } \\
347\end{array}$ \\
\hline [11] & Melimine & $\begin{array}{l}\text { Commercial contact lenses (etafilcon } \\
\text { A) }\end{array}$ & $\begin{array}{l}\text { Immobilization by the free AMP amines using 1-ethyl-3- } \\
\text { (3-dimethylaminopropyl)carbodiimide } \\
\text { - AMP orientation was not controlled } \\
\text { - No spacers }\end{array}$ & $\begin{array}{l}\text { P. aeruginosa } 6294 \text {, P. aeruginosa ATCC } \\
\text { 15442, S. aureus Saur31, S. aureus CK5, S. } \\
\text { pneumoniae } 010\end{array}$ \\
\hline [76] & Melimine & Glass coverslips & $\begin{array}{l}\text { Immobilization through the free AMP amines using two } \\
\text { different strategies: } \\
\text { - Using EDC after previous activation of the OH groups } \\
\text { of the glass surface with } 4 \text {-azidobenzoic acid (ABA) } \\
\text { and irradiation with UV-light ( } 320 \mathrm{~nm} \text { ) } \\
\text { - As above but using 4-fluoro-3-nitrophenyl azide } \\
\text { (FNA) instead of ABA } \\
\text { - AMP orientation was not controlled } \\
\text { - No spacers } \\
\text { - Different AMP densities were tested }\end{array}$ & S. aureus strain $38, P$. aeruginosa PA01 \\
\hline [70] & Cathelin LL37 & $\begin{array}{l}\text { Silanized titanium surfaces: } \\
\text { Using glycidyloxypropyl } \\
\text { triethoxysilane (epoxy silane) } \\
\text { 3-aminopropyl triethoxysilane(amino } \\
\text { silane) }\end{array}$ & $\begin{array}{l}\text { - } N \text {-maleimidopropionic acid succinimide ester } \\
\text { - } R \text { - } N \text {-hydroxysuccinimidyl-ö-maleimidyl-PEG } \\
\text { - Effect of AMP orientation was tested } \\
\text { - Eifferen of PEGylated spacers was tested } \\
\text { - DMPs densities were tested }\end{array}$ & E. coli strain $\mathrm{K} 12$ \\
\hline [77] & E14LKK & Oxidized polyethylene films (ox-PE) & $\begin{array}{l}\text { Immobilization by the terminal AMP amine (using } \\
\text { protected E14LKK side chains amines) with and without } \\
\text { PEGylated spacer onto ox-PE using 1-ethyl-3-(3- } \\
\text { aminopropyl)-carbodiimide } \\
\text { - AMP orientation was controlled } \\
\text { - Effect of PEGylated spacers was tested }\end{array}$ & E. coli ATCC 25922 \\
\hline [56] & FKVKFKVKFK & PEG-PS Resin beads & $\begin{array}{l}\text { Peptide-resin conjugates were synthesized by using } \\
\text { Fmoc ( } 9 \text {-fluorenylmethoxycarbonyl)-chemistry. To } \\
\text { investigate the effect of the resin on the activity, the } \beta \text { - } \\
\text { sheet peptide was conjugated with MBHA-resin }\end{array}$ & $\begin{array}{l}\text { S. aureus ATCC } 6538, \text { Micrococcus luteus } \\
\text { ATCC } 9341, \text { P. aeruginosa ATCC9027, } \\
\text { E. coli ATCC } 25922\end{array}$ \\
\hline [78] & $6 \mathrm{~K} 8 \mathrm{~L}$ & PEG-PS resin beads & $\begin{array}{l}\text { The peptide was synthesized by solid-phase peptide } \\
\text { synthesis on a PEG-modified polystyrene resin (PEG-PS) } \\
\text { using Fmoc (9-fluorenylmethoxycarbonyl)-chemistry. } \\
\text { The antimicrobial activity of the peptide-resin conjugate } \\
\text { was evaluated against different microorganisms. }\end{array}$ & $\begin{array}{l}\text { B. subtilis (wild-type PB2, } 168 \text { Marburg } \\
\text { strain27), E. coli O157: H7 ATCC } 33150 \text {, } \\
\text { Kluyveromyces marxianus, L. } \\
\text { monocytogenes ATCC } 689426, P . \\
\text { fluorescence, Salmonella typhimurium H } \\
3380 \text { phage type DT 104, Serratia } \\
\text { liquefasciens and S. aureus ATCC } 13566 .\end{array}$ \\
\hline [71] & $\begin{array}{l}122 \text { variant } \\
\text { peptides of } 2 \\
\text { starting } \\
\text { sequences: } \\
\text { Bac } 2 \mathrm{~A} \text { and } \\
\text { Indolicidin }\end{array}$ & $\begin{array}{l}\text { Cellulose } \\
\text { bifunctional resin TGS (1-6-dichloro- } \\
\text { 1- Beta-dideoxy-Beta-fructofuranosM- } \\
\text { chloro-4-deoxy-galactopyranoside) } \\
\mathrm{NH}_{2} / \mathrm{RAM} \text { ( } p \text {-[(R,S)-a-[1-(9H-fluren-9- } \\
\text { yl)-methoxyformamido]-2,4- } \\
\text { dimethoxybenzyl]-phen-oxyacetic } \\
\text { acid) } \\
\text { Microtiter plate }\end{array}$ & $\begin{array}{l}\text { Peptides were: } \\
\text { - directly synthesized on a cellulose support using a } \\
\text { cellulose-amino-hydroxypropyl ether (CAPE) linker } \\
\text { chemistry or; } \\
\text { - directly synthesized onto a bifunctional resin or; } \\
\text { - directly bound to the microtiter plate via biotin- } \\
\text { streptavidin interaction. } \\
\text { - AMP orientation was controlled } \\
\text { - No spacers }\end{array}$ & $\begin{array}{l}\text { Mini-Tn5-luxfliC::lux CDABE strain } \\
\text { H1001 of } P \text {. aeruginosa PAO1, S. aureus } \\
\text { ATCC 25923, C. albicans (lab isolate). }\end{array}$ \\
\hline
\end{tabular}


immobilization was performed directly through the free peptide amines (the $N$-terminal amino acid or the lysine side chain) without a specific control on the orientation of the peptide onto the surface. An apparent increase in efficacy was observed when the peptide was covalently attached to the surface, which was ascribed to a possibly higher relative surface availability of the peptide, in contrast to the adsorption process where peptide aggregation could produce uneven peptide distribution.

The effect of $\alpha$-helix secondary structure of immobilized AMP was also studied by Haynie et al. [67]. They demonstrated that only those immobilized peptides still retaining their ability to form amphipathic $\alpha$-helices had antibacterial activity. Likewise, in the work of Cho et al. [56], the secondary $\beta$-sheet structure was essential for antibacterial activity. Thus, these studies indicate that the biocidal activity of immobilized AMPs is dependent on the presence of a well-established secondary structure.

Other important activity-modulating parameters include the length, flexibility and kind of spacer between the active sequences and the solid matrices $[67,69,70]$, the AMP surface density $[1,68,69]$, and orientation after immobilization [1,11,67-70,7678]. These parameters are discussed below.

\subsection{Solid supports and chemical coupling strategies}

A wide variety of solid supports has been assessed for production of surfaces with immobilized AMPs, including polymeric brushes and resins $[1,56,67,69,71,77,78]$, metal (e.g. silanized titanium) [70], glass coverslips [76], model surfaces (e.g. self-assembled monolayers) [68], microtitre plates [71] and even commercial contact lenses [11].

As shown in Table 1, the chemical strategies behind covalent immobilization of peptides differ depending on the sequence, orientation and position of the specific AMP, the presence/absence of a spacer, or the spacer properties such as length and flexibility.

Peptide immobilization may be carried out in a relatively random manner, e.g. through formation of amide bonds between amine groups from the pre-synthesized peptide and surface carboxyls (or the other way around, i.e. carboxyls from the peptide reacting with surface amines), as in Refs. [10,43,44] (Table 1). Alternatively, peptide immobilization can be controlled through peptide construction (or immobilization) on the surface by chemoselective formation of a peptide-surface covalent bond, enabling tethering in a predictable and defined fashion.

Controlled immobilization is obviously preferred over random tethering, as the former can be designed (i) to maintain peptide structural motifs known to be relevant for activity, and (ii) to allow exposure and flexibility that more closely mimic the behaviour of soluble AMPs. Uncontrolled immobilization can be especially detrimental when involving peptide amine groups, as these amine groups are normally provided by lysines which are key amino acids in the majority of cationic amphipathic AMPs [39-42].

The best way to control orientation of immobilized peptides is to synthesize them directly onto the solid support (e.g. polyamide resins, PEG-modified polystyrene resins, cellulose), as done in Refs. $[28,35,39]$ or $[46]$ (Table 1$)$. To this end, standard solid-phase peptide synthesis (SPPS) methods may be used, such as the wellestablished $\mathrm{Fmoc} /{ }^{t} \mathrm{Bu}$ strategy [79]. In this strategy selectively protected amino acids are incorporated stepwise into the growing peptide chain that is built from its $C$ - to its $N$-terminal residue. Once the peptide sequence is assembled, convenient treatment to cleave off the amino acid side-chain-protecting groups is performed.

An alternative to building the peptide directly onto the surface is to pre-synthesize a peptide chain with a specific building block incorporated in a selected position. This peptide chain can subsequently be chemoselectively attached to an adequately functional- ized surface. The most common approaches involve incorporation of an additional cysteine into the peptide chain (e.g. [1]) or exploiting a cysteine already available in the native sequence (if not crucial for AMP activity), taking advantage of chemical reactions specific to the thiol group. These reactions may include, as depicted in Fig. 2, (i) disulfide bond formation between peptide and surface thiols, as well as specific reactions of the peptide Cys thiol with (ii) surface-bound maleimide groups $[1,42]$, or (iii) surface-bound epoxides (though these are generally reactive towards any nucleophiles, including lysine amines, and hence are not truly chemoselective).

Other chemoselective approaches not involving Cys or other thiol donors have been proposed more recently, namely those involving Huisgen 1,3-dipolar cycloadditions, the so-called clickreactions [80]. Here, the peptide can bear an additional azide (e.g. from incorporation of 6-azidohexanoic acid) or an alkyne donor (e.g. from incorporation of propynoic acid) to be "clicked on" surface-bound alkyne or azide groups, respectively.

Both epoxide and click-based approaches have been used to immobilize peptides and proteins onto surfaces (e.g. [81-83]), but examples of their application to AMP tethering are still scarce.

Irrespective of alternatives available for peptide tethering onto surfaces, careful comparative investigation of different strategies must be carried out, in which the influence of peptide-surface spacers, coupling chemistries and support materials on antimicrobial activity should be thoroughly analyzed. Only Hilpert et al. [71] have assessed the effect of different support materials on the antimicrobial activity, and found that, at least for their specific systems, the supports did not affect the activity of the tested peptides.

\subsection{Influence of the spacer}

Although some studies demonstrated that immobilized AMPs have antimicrobial activity without incorporation of a spacer $[11,68,71,76]$, most protocols presented a spacer attachment step $[1,56,67,69,70,77,78]$, particularly with a PEG spacer with a MW ranging from 3000 to $5400[56,69,70,77,78]$. The utilization of PEG as a spacer presents several advantages. This polymer can create non-adhesive surfaces due to its non-fouling characteristics, thus preventing non-specific peptide binding to the surface and shielding the peptides from the hydrophobic nature of a particular biomaterial [56,77]. Studies comparing AMP immobilization with and without PEGylated spacers demonstrated that some immobilized AMPs are only bactericidal when a PEGylated spacer was used $[56,69,70,77]$. For example, Gabriel et al. [70] demonstrated that the LL37 peptide bound to titanium through a PEGylated spacer was capable of killing Escherichia coli on contact. In marked contrast, LL37 peptide attached directly to the titanium surface displayed no antibacterial activity. The authors suggest that the use of a long, flexible PEG spacer provided a parallel peptide orientation and lateral mobility that were required for bactericidal activity. Bagheri et al. [69] also analyzed the influence of PEGylated spacer length $(3000,400$ and $200 \mathrm{Da})$ on bactericidal activity of an amphipathic model KLAL peptide and magainin-derived MK5E. They demonstrated that the antimicrobial activity of these peptides distinctly decreased with reduction in the spacer length, suggesting that the increased flexibility associated with longer spacers maximizes the antimicrobial activity of immobilized peptides [69].

However, these results contradict those of Haynie et al. [67] whose experiments indicated no difference in bactericidal activity whether peptides were conjugated to the support with a two-carbon or a six-carbon chain linker [67]. In addition, Hilpert et al. [71] reported that short 9-mers covalently linked without spacer have bactericidal activity. They suggested an electrostatic interference and destabilization rather than a penetrating mechanism. 


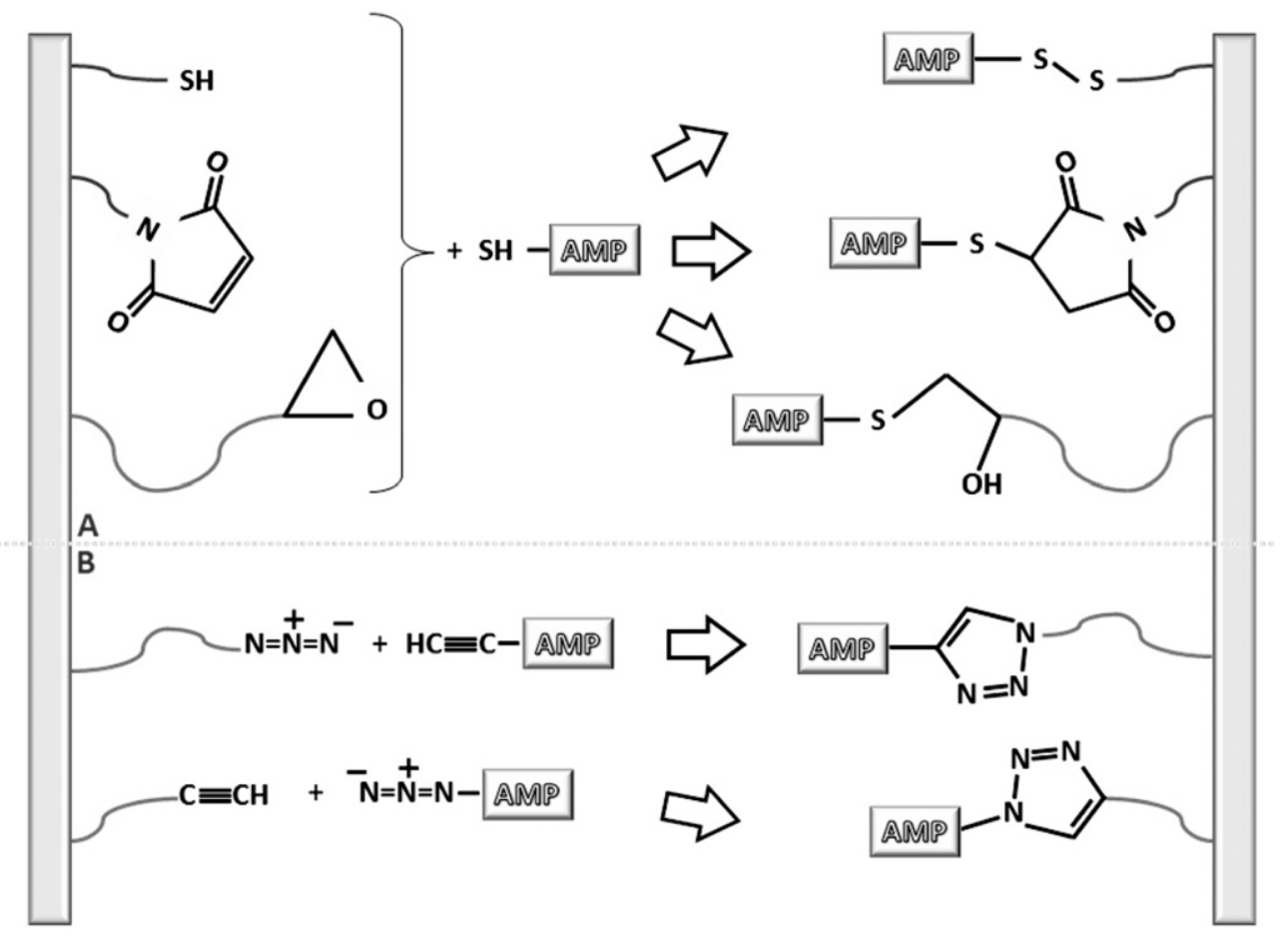

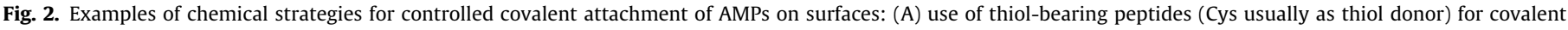

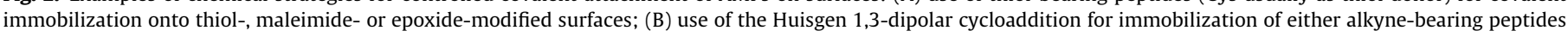
onto azide-modified surfaces or azide-bearing peptides onto alkyne-modified surfaces.

Comparison of these studies is difficult, since AMPs, support materials, coupling chemistry and peptide orientations differ from study to study. However, one can speculate that the requirement for a spacer is directly associated with the mode of action of the specific AMP.

\subsection{Peptide concentration}

Peptide surface concentration depends on the immobilization strategy used, as limited accessibility of the peptide reactive groups and different coupling procedures can affect the efficiency of peptide immobilization. Most studies indicate that peptide concentrations, albeit important, do not appear to be the most critical parameter for antimicrobial activity $[1,69,70,76]$. Gabriel et al. [70] observed that the bactericidal activity of LL37 immobilized onto titanium surfaces was independent of the peptide concentration [70]. Glinel et al. [1] demonstrated that the biocidal activity of magainin I was not substantially reduced as the concentration of immobilized peptide was reduced. Bagheri et al. [69] reported a study aimed to determine the effect on bactericidal activity of different surface peptide densities and spacer lengths. These studies demonstrated that an increase in the loading capacity of the resin was not sufficient to compensate for the decrease in activity due to reduction of the spacer length. Based on these observations, they concluded that spacer length has a more profound impact on activity than peptide concentration. Further, the maximum peptide loading concentration was obtained with the $C$-terminal coupling strategy, which correlated with higher Minimal Inhibitory Concentration (MICs), suggesting that immobilization orientation can compensate for low peptide loading [69].

Despite these reports, which strongly support the concept that peptide surface loading levels are not a key factor in the antimicrobial activity of immobilized AMP, other studies have provided evidence that the effects of peptide surface concentration cannot be disregarded. For instance, Chen et al. [76] evaluated the effect of melimine concentration after immobilization by two different bifunctional azides (4-fluoro-3-nitrophenyl azide (FNA) and 4azidobenzoic acid (ABA)) as crosslinking reagents. In this study, the higher concentration of the peptide via $A B A$ immobilization correlated with a more profound antibacterial activity. Humblot et al. [68] correlated low peptide concentrations with bacteriostatic rather than bacteriocidal effect of immobilized magainin I, explaining that the low peptide concentration precludes the possibility of multiple peptide entries into the cell membrane. In addition, Hilpert et al. [71] studied the effect of immobilized peptide density on antimicrobial activity by utilizing different concentrations of biotinylated peptide solutions with streptavidin-coated plates. Antimicrobial activity was clearly concentration dependent, decreasing sigmoidally as a function of decreasing peptide concentration.

\subsection{Peptide orientation after immobilization}

Different strategies for surface binding of peptides have been conducted on different chain positions, such as C-terminal, $\mathrm{N}$-terminal and/or $\mathrm{N}$-side-chain peptide attachment. As a result, different peptide orientations and flexibility were obtained, which could be correlated with differential antimicrobial activities. The chain position was determined based upon (i) previous knowledge of peptide robustness to changes in given positions, i.e. on its ability to retain or lose antimicrobial activity upon deletion of $\mathrm{N}$-terminal or $\mathrm{C}$-terminal amino acids or amino acid segments; (ii) the availability of functional groups suitable for a particular coupling chemistry; or (iii) the promotion of parallel alignment of peptide chains $[56,67,68,70]$. The studies of Gabriel et al. [70] and Steven et al. [77] compared the antimicrobial efficiency of $\mathrm{N}$-terminally and $\mathrm{N}$-side-chain immobilized peptides. They performed site-specific activation and coupling by blocking the 
undesired functional groups. Even though the experimental AMPs were different in the respective studies, only $\mathrm{N}$-terminally attached peptides displayed antimicrobial activity. Gabriel et al. [70] concluded that only $\mathrm{N}$-terminal conjugation permitted the appropriate parallel orientation of the peptide helices, which is required for interaction among the peptide molecules and between the peptides and the lipid double layer during membrane pore formation. These results are supported by the reported key role of basic lysine side-chains (and of those from other basic amino acids, as arginine or histidine) in the bioactivity of cationic AMP [39-42], which could explain the deleterious effect of AMP immobilization through Lys $\varepsilon$-amino groups towards antimicrobial activity. The possibility of $C$-terminal peptide immobilization should be considered as this orientation may achieve similar specific activity as $N$-terminal conjugation. Bagheri et al. [69] compared the activity profile of $\mathrm{C}$-terminal, $\mathrm{N}$-terminal and $\mathrm{N}$-side-chain immobilized AMP sequences. Slightly different results were obtained depending on the specific peptide sequence and bacteria tested. C-terminally attached AMPs displayed higher MICs, compared to $\mathrm{N}$-terminal and $\mathrm{N}$-side-chain immobilization. The $\mathrm{N}$-immobilization orientations presented similar results, suggesting that the blockage of the cationic Lys side chains was of minor importance to the overall antimicrobial activity. However, it is possible that the observed reactivity pattern may be specific to the systems used by these authors, where the AMP orientation appeared to be less relevant when peptides were immobilized using long and flexible spacers [69]. Hilpert et al. [71] used a different strategy to screen the efficiency of immobilized AMPs. They rearranged the sequence of a known active peptide and C-terminally immobilized the different variants. They concluded that the placement of cationic residues close to the linker site correlated with increased antimicrobial activity as compared with peptides with cationic residues localized to the $\mathrm{N}$-terminus or within the middle portion of the peptide. The positioning of hydrophobic residues proximal to the $N$-terminus was critical to the activity of their immobilized AMPs.

\subsection{Activity efficiency of immobilized AMPs}

Only a few studies have described an experimental comparison of soluble and immobilized AMPs [56,67,69,71]. However, a straightforward comparison between MICs of soluble and immobilized AMPs is very difficult because precise quantification of immobilized AMP can be problematic. In most cases the immobilized AMPs displayed an increase in their MIC value compared to the soluble peptide. In studies by Haynie et al. [67] the immobilized AMPs presented a 50-fold higher MIC compared to soluble peptides. These investigators suggested that the coupling chemistry may have resulted in more covalently bound peptide in the resin interior than on the surface, which could explain the higher concentration needed for activity. Cho et al. [56] found an extensive variation range in the observed MIC values which were augmented 8- or 64 -fold depending on the bacteria evaluated (E. coli, Micrococcus luteus and $S$. aureus more sensitive; $P$. aeruginosa less susceptible). In the Bagheri et al. [69] studies, the active concentrations increased about 100 -fold from the micromolar MICs of the soluble peptides to the milimolar range of the immobilized-AMPs. All these studies reported MIC increases that varied with peptide and bacteria specificity.

However, Hilpert et al. [71] compared soluble MICs and inhibition of luminescence by immobilized AMPs. No correlation of antimicrobial activity was observed between soluble and immobilized AMPs, as inactive soluble AMPs presented activity when immobilized, and some active soluble AMPs lost activity when immobilized.

\subsection{Cytotoxicity}

KLAL and MK5E are examples of immobilized AMPs for which haemolytic activity has been assessed. The KLAL- and MK5Esoluble haemolytic concentrations (EC25) were at least 16-fold higher than the respective MIC. Moreover, the haemolytic activity levels of the immobilized-peptide beads and the bare beads were indistinguishable from each other. This observation leads to the conclusion that both immobilized peptides at their MICs are inactive toward red blood cells [69]. Hilpert et al. [71] assessed cytotoxicity of a battery of immobilized peptides through human red blood cell haemolysis. They reported that the immobilization of AMPs had a reduced haemolytic activity when compared with the soluble counterpart. Thus, these initial studies indicate that peptide immobilization does not enhance the haemolytic properties of the peptides, and may actually reduce potential haemolysis when compared to soluble peptides.

\subsection{Long-term stability}

In order to check the activity persistence of immobilized peptides, investigators have subjected the modified surfaces to various harsh procedures, such as washing operations, heat treatments, $\mathrm{pH}$ variations and long-term activity assessment $[11,67,68,78]$. In the washing influence study, two different AMP-modified resin beads were extensively washed without loss of antimicrobial activity $[67,78]$. The heat stability experiment was conducted to evaluate whether exposure of AMP to autoclaving $\left(121^{\circ} \mathrm{C}\right.$ for $\left.20 \mathrm{~min}\right)$ or to a dry oven $\left(200^{\circ} \mathrm{C}\right.$ for $30 \mathrm{~min}$ ) would alter the ability of the peptide to inhibit bacterial growth. The bactericidal efficacy of the heat-treated 6K8L was maintained under both heating conditions [78]. In addition, the antimicrobial efficacy of melimine was maintained during autoclaving [11]. Cole et al. [84] verified that the levels of melimine in lenses after removal, cleaning and sterilization did not differ from those determined before $24 \mathrm{~h}$ of use. The effect of $\mathrm{pH}$ on the modified surface was assessed. The peptide 6K8L immobilized on PEG-poly(styrene) resin beads retained its antimicrobial activity over a pH range of 3.5-7 in citrate buffer, although bacterial killing was significantly greater at $\mathrm{pH} 3.5$ than at $\mathrm{pH} 7$ [78], possibly due to the higher positive charge at the lower $\mathrm{pH}$. Humblot et al. [68] assayed the stability of antimicrobial activity of immobilized peptide at various times over a 6 month period. Samples were cleaned, dried and stored at $4{ }^{\circ} \mathrm{C}$, between each antibacterial activity assay. The results showed that the peptide remained active over the 6 month period, even though the activity of the immobilized peptide was reduced at the 6 month time point.

All these studies, although limited, point to remarkably high long-term stability and resistance of immobilized AMP to environmental conditions.

\section{Conclusions}

Infections associated with the use of biomaterials remain one of the major barriers to the long-term use of medical devices in patients. Colonization of biomedical surfaces is considered the basis for biofilm formation and infection. The establishment of a biofilm results in lower antibiotic activity, and higher antibiotic resistance, which in turn can demand implant removal. There is a clear need for a broad-spectrum antimicrobial that prevents colonization of biomaterials, without damaging mammalian cells, that minimizes the potential for bacterial resistance, and that is stable throughout the sterilization process. AMPs have enormous potential to fulfil all these requirements and are therefore suitable for the generation of antimicrobial surfaces. Different approaches may be applied to improve surfaces with such antimicrobial agents. Covalent 
immobilization of AMPs to surfaces can offer important advantages, including long-term stability and lower toxicity when compared to leach- or release-methodologies. The implications of the studies reviewed herein suggest that immobilized AMPs may be effective in the prevention of biofilm formation by reduction of microorganism survival post-contact with the coated material. The mechanisms of action behind each antimicrobial coating vary according to the specific AMP, chemistry and support used. Moreover, the overall comparison of results suggests that free and immobilized AMPs may act through different mechanisms. Further studies may clarify the mechanisms of action underlying immobilized AMPs and their potential use in health applications as antimicrobial coatings of medical devices.

\section{Acknowledgements}

The authors would like to thank the Portuguese Foundation for Science and Technology (FCT) (Ref. PTDC/CTM/101484/2008) and FEDER (Ref. FCOMP-01-0124-FEDER-009400) for co-funding the research project.

\section{Appendix A. Figures with essential colour discrimination}

Certain figures in this article, particularly Figure 1, is difficult to interpret in black and white. The full colour image can be found in the on-line version, at doi:10.1016/j.actbio.2010.11.005.

\section{Appendix B. Supplementary data}

Supplementary data associated with this article can be found, in the online version, at doi:10.1016/j.actbio.2010.11.005.

\section{References}

[1] Glinel K, Jonas AM, Jouenne T, Leprince J, Galas L, Huck WT. Antibacterial and antifouling polymer brushes incorporating antimicrobial peptide. Bioconj Chem 2009;20(1):71-7.

[2] Vila J, Soriano A, Mensa J. Molecular basis of microbial adherence to prosthetic materials. Role of biofilms in prosthesis-associated infection. Enferm Infecc Microbiol Clin 2008;26(1):48-54. quiz 55.

[3] Hetrick EM, Schoenfisch MH. Reducing implant-related infections: active release strategies. Chem Soc Rev 2006;35(9):780-9.

[4] Darouiche RO. Treatment of infections associated with surgical implants. N Engl J Med 2004;350(14):1422-9.

[5] Zhao L, Chu PK, Zhang Y, Wu Z. Antibacterial coatings on titanium implants. J Biomed Mater Res B Appl Biomater 2009;91(1):470-80.

[6] Dee KC, Puleo DA, Bizios R. An introduction to tissue-biomaterial interactions. New York: Wiley-Liss; 2002.

[7] Subramani K, Jung RE, Molenberg A, Hammerle CH. Biofilm on dental implants: a review of the literature. Int J Oral Maxillofac Implants 2009;24(4):616-26.

[8] Fey PD, Olson ME. Current concepts in biofilm formation of Staphylococcus epidermidis. Future Microbiol 2010;5(6):917-33.

[9] de Carvalho CC. Biofilms: recent developments on an old battle. Recent Pat Biotechnol 2007;1(1):49-57.

[10] Costerton JW, Stewart PS, Greenberg EP. Bacterial biofilms: a common cause of persistent infections. Science 1999;284(5418):1318-22.

[11] Willcox MD, Hume EB, Aliwarga Y, Kumar N, Cole N. A novel cationic-peptide coating for the prevention of microbial colonization on contact lenses. J App Microbiol 2008;105(6):1817-25.

[12] Lewis K. Riddle of biofilm resistance. Antimicrob Agents Chemother 2001;45(4):999-1007.

[13] Monteiro DR, Gorup LF, Takamiya AS, Ruvollo-Filho AC, de Camargo ER, Barbosa DB. The growing importance of materials that prevent microbial adhesion: antimicrobial effect of medical devices containing silver. Int Antimicrob Agents 2009;34(2):103-10.

[14] Gooderham WJ, Bains M, McPhee JB, Wiegand I, Hancock RE. Induction by cationic antimicrobial peptides and involvement in intrinsic polymyxin and antimicrobial peptide resistance, biofilm formation, and swarming motility of PsrA in Pseudomonas aeruginosa. J Bacteriol 2008;190(16): 5624-34.

[15] Bagge N, Schuster M, Hentzer M, Ciofu O, Givskov M, Greenberg EP, et al Pseudomonas aeruginosa biofilms exposed to imipenem exhibit changes in global gene expression and beta-lactamase and alginate production. Antimicrob Agents Chemother 2004;48(4):1175-87.
[16] Ahmed NA, Petersen FC, Scheie AA. AI-2/LuxS is involved in increased biofilm formation by Streptococcus intermedius in the presence of antibiotics. Antimicrob Agents Chemother 2009;53(10):4258-63.

[17] Hoffman LR, D'Argenio DA, MacCoss MJ, Zhang Z, Jones RA, Miller SI. Aminoglycoside antibiotics induce bacterial biofilm formation. Nature 2005;436(7054):1171-5.

[18] Harbers GM, Emoto K, Greef C, Metzger SW, Woodward HN, Mascali JJ, et al. A functionalized poly(ethylene glycol)-based bioassay surface chemistry that facilitates bio-immobilization and inhibits non-specific protein, bacterial, and mammalian cell adhesion. Chem Mater 2007;19(18):4405-14.

[19] Chapman RG, Ostuni E, Liang MN, Meluleni G, Kim E, Yan L, et al. Polymeric thin films that resist the adsorption of proteins and the adhesion of bacteria. Langmuir 2001;17(4):1225-33.

[20] Goncalves IC, Martins MC, Barbosa MA, Naeemi E, Ratner BD. Selective protein adsorption modulates platelet adhesion and activation to oligo(ethylene glycol)-terminated self-assembled monolayers with C18 ligands. J Biomed Mater Res A 2009;89(3):642-53.

[21] Chung DW, Papadakis SE, Yam KL. Evaluation of a polymer coating containing triclosan as the antimicrobial layer for packaging materials. Int J Food Sci Technol 2003;38(2):165-9.

[22] Leung D, Spratt DA, Pratten J, Gulabivala K, Mordan NJ, Young AM. Chlorhexidinereleasing methacrylate dental composite materials. Biomaterials 2005;26(34): 7145-53.

[23] Ravikumar T, Murata H, Koepsel RR, Russell AJ. Surface-active antifungal polyquaternary amine. Biomacromolecules 2006;7(10):2762-9.

[24] Bach A, Darby D, Bottiger B, Bohrer H, Motsch J, Martin E. Retention of the antibiotic teicoplanin on a hydromer-coated central venous catheter to prevent bacterial colonization in postoperative surgical patients. Intensive Care Med 1996;22(10):1066-9.

[25] Jose B, Antoci Jr V, Zeiger AR, Wickstrom E, Hickok NJ. Vancomycin covalently bonded to titanium beads kills Staphylococcus aureus. Chem Biol 2005;12(9):1041-8.

[26] Kilic D, Agalar C, Ozturk E, Denkbas EB, Cime A, Agalar F. Antimicrobial activity of cefazolin-impregnated mesh grafts. ANZ J Surg 2007;77(4):256-60.

[27] Gallardo-Moreno AM, Pacha-Olivenza MA, Saldana L, Perez-Giraldo C, Bruque $\mathrm{JM}$, Vilaboa $\mathrm{N}$, et al. In vitro biocompatibility and bacterial adhesion of physico-chemically modified Ti6Al4V surface by means of UV irradiation. Acta Biomater 2009;5(1):181-92.

[28] Jansen B, Kohnen W. Prevention of biofilm formation by polymer modification. J Ind Microbiol 1995;15(4):391-6.

[29] Martins MC, Wang D, Ji J, Feng L, Barbosa MA. Albumin and fibrinogen adsorption on cibacron blue F3G-A immobilised onto PU-PHEMA (polyurethane-poly(hydroxyethylmethacrylate)) surfaces. J Biomater Sci Polym Ed 2003;14(5):439-55.

[30] Zhang F, Zhang Z, Zhu X, Kang ET, Neoh KG. Silk-functionalized titanium surfaces for enhancing osteoblast functions and reducing bacterial adhesion. Biomaterials 2008;29(36):4751-9.

[31] Flemming RG, Capelli CC, Cooper SL, Proctor RA. Bacterial colonization of functionalized polyurethanes. Biomaterials 2000;21(3):273-81.

[32] Singla AK, Chawla M. Chitosan: some pharmaceutical and biological aspectsan update. J Pharm Pharmacol 2001;53(8):1047-67.

[33] Murata H, Koepsel RR, Matyjaszewski K, Russell AJ. Permanent, non-leaching antibacterial surface-2: how high density cationic surfaces kill bacterial cells. Biomaterials 2007;28(32):4870-9.

[34] Aumsuwan N, Danyus RC, Heinhorst S, Urban MW. Attachment of ampicillin to expanded poly(tetrafluoroethylene): surface reactions leading to inhibition of microbial growth. Biomacromolecules 2008;9(7):1712-8.

[35] Cevher E, Orhan Z, Mulazimoglu L, Sensoy D, Alper M, Yildiz A, et al. Characterization of biodegradable chitosan microspheres containing vancomycin and treatment of experimental osteomyelitis caused by methicillin-resistant Staphylococcus aureus with prepared microspheres. Int J Pharm 2006;317(2):127-35.

[36] Faber C, Stallmann HP, Lyaruu DM, Joosten U, von Eiff C, van Nieuw Amerongen A, et al. Comparable efficacies of the antimicrobial peptide human lactoferrin 1-11 and gentamicin in a chronic methicillin-resistant Staphylococcus aureus osteomyelitis model. Antimicrob Agents Chemother 2005;49(6):2438-44.

[37] Aumsuwan N, Heinhorst S, Urban MW. Antibacterial surfaces on expanded polytetrafluoroethylene; penicillin attachment. Biomacromolecules 2007;8(2): 713-8.

[38] Palumbi SR. Humans as the world's greatest evolutionary force. Science 2001;293(5536):1786-90.

[39] Andreu D, Rivas L. Animal antimicrobial peptides: an overview. Biopolymers 1998;47(6):415-33.

[40] Rivas L, Luque-Ortega JR, Andreu D. Amphibian antimicrobial peptides and Protozoa: lessons from parasites. Biochim Biophys Acta 2009;1788(8):1570-81.

[41] Gordon YJ, Romanowski EG, McDermott AM. A review of antimicrobial peptides and their therapeutic potential as anti-infective drugs. Curr Eye Res 2005;30(7):505-15.

[42] Guani-Guerra E, Santos-Mendoza T, Lugo-Reyes SO, Teran LM. Antimicrobial peptides: general overview and clinical implications in human health and disease. Clin Immunol 2010;135(1):1-11.

[43] Perron GG, Zasloff M, Bell G. Experimental evolution of resistance to an antimicrobial peptide. Proc Biol Sci 2006;273(1583):251-6.

[44] Reddy KV, Yedery RD, Aranha C. Antimicrobial peptides: premises and promises. Int J Antimicrob Agents 2004;24(6):536-47. 
[45] van't Hof W, Veerman EC, Helmerhorst EJ, Amerongen AV. Antimicrobial peptides: properties and applicability. Biol Chem 2001;382(4):597-619.

[46] Li M, Cha DJ, Lai Y, Villaruz AE, Sturdevant DE, Otto M. The antimicrobial peptide-sensing system aps of Staphylococcus aureus. Mol Microbiol 2007;66(5):1136-47.

[47] Li M, Lai Y, Villaruz AE, Cha DJ, Sturdevant DE, Otto M. Gram-positive threecomponent antimicrobial peptide-sensing system. Proc Natl Acad Sci USA 2007;104(22):9469-74.

[48] Otto M. Bacterial sensing of antimicrobial peptides. Contrib Microbiol 2009; $16: 136-49$

[49] Peschel A, Collins LV. Staphylococcal resistance to antimicrobial peptides of mammalian and bacterial origin. Peptides 2001;22(10):1651-9.

[50] Peschel A, Jack RW, Otto M, Collins LV, Staubitz P, Nicholson G, et al. Staphylococcus aureus resistance to human defensins and evasion of neutrophil killing via the novel virulence factor $\mathrm{MprF}$ is based on modification of membrane lipids with l-lysine. J Exp Med 2001;193(9): 1067-76.

[51] Cao M, Helmann JD. The Bacillus subtilis extracytoplasmic-function sigmaX factor regulates modification of the cell envelope and resistance to cationic antimicrobial peptides. J Bacteriol 2004;186(4):1136-46.

[52] Clarke SR, Foster SJ. IsdA protects Staphylococcus aureus against the bactericidal protease activity of apolactoferrin. Infect Immun 2008;76(4): 1518-26.

[53] Vuong C, Voyich JM, Fischer ER, Braughton KR, Whitney AR, DeLeo FR, et al. Polysaccharide intercellular adhesin (PIA) protects Staphylococcus epidermidis against major components of the human innate immune system. Cell Microbiol 2004;6(3):269-75.

[54] Zasloff M. Antimicrobial peptides of multicellular organisms. Nature 2002;415(6870):389-95

[55] Hancock RE. Peptide antibiotics. Lancet 1997;349(9049):418-22.

[56] Cho WM, Joshi BP, Cho H, Lee KH. Design and synthesis of novel antibacterial peptide-resin conjugates. Bioorg Med Chem Lett 2007;17(21):5772-6.

[57] Statz AR, Park JP, Chongsiriwatana NP, Barron AE, Messersmith PB. Surfaceimmobilised antimicrobial peptoids. Biofouling 2008;24(6):439-48.

[58] Deslouches B, Gonzalez IA, DeAlmeida D, Islam K, Steele C, Montelaro RC, et al. De novo-derived cationic antimicrobial peptide activity in a murine model of Pseudomonas aeruginosa bacteraemia. J Antimicrob Chemother 2007;60(3): 669-72.

[59] Novak KF, Diamond WJ, Kirakodu S, Peyyala R, Anderson KW, Montelaro RC, et al. Efficacy of the de novo-derived antimicrobial peptide WLBU2 against oral bacteria. Antimicrob Agents Chemother 2007;51(5):1837-9.

[60] Deslouches B, Islam K, Craigo JK, Paranjape SM, Montelaro RC, Mietzner TA. Activity of the de novo engineered antimicrobial peptide WLBU2 against Pseudomonas aeruginosa in human serum and whole blood: implications for systemic applications. Antimicrob Agents Chemother 2005;49(8):3208-16.

[61] Deslouches B, Phadke SM, Lazarevic V, Cascio M, Islam K, Montelaro RC, et al. De novo generation of cationic antimicrobial peptides: influence of length and tryptophan substitution on antimicrobial activity. Antimicrob Agents Chemother 2005;49(1):316-22.

[62] Levin M, Quint PA, Goldstein B, Barton P, Bradley JS, Shemie SD, et al. Recombinant bactericidal/permeability-increasing protein (rBPI21) as adjunctive treatment for children with severe meningococcal sepsis: a randomised trial. rBPI21 Meningococcal Sepsis Study Group. Lancet 2000;356(9234):961-7.

[63] Giroir BP, Scannon PJ, Levin M. Bactericidal/permeability-increasing proteinlessons learned from the phase III, randomized, clinical trial of rBPI21 for adjunctive treatment of children with severe meningococcemia. Crit Care Med 2001;29(7 Suppl):S130-135.

[64] Brogden KA. Antimicrobial peptides: pore formers or metabolic inhibitors in bacteria? Nat Rev Microbiol 2005;3(3):238-50.
[65] Bastos M, Bai G, Gomes P, Andreu D, Goormaghtigh E, Prieto M. Energetics and partition of two cecropin-melittin hybrid peptides to model membranes of different composition. Biophys J 2008;94(6):2128-41.

[66] Melo MN, Ferre R, Castanho MA. Antimicrobial peptides: linking partition, activity and high membrane-bound concentrations. Nat Rev Microbiol 2009;7(3):245-50.

[67] Haynie SL, Crum GA, Doele BA. Antimicrobial activities of amphiphilic peptides covalently bonded to a water-insoluble resin. Antimicrob Agents Chemother 1995;39(2):301-7.

[68] Humblot V, Yala JF, Thebault P, Boukerma K, Hequet A, Berjeaud JM, et al. The antibacterial activity of Magainin I immobilized onto mixed thiols selfassembled monolayers. Biomaterials 2009;30(21):3503-12.

[69] Bagheri M, Beyermann M, Dathe M. Immobilization reduces the activity of surface-bound cationic antimicrobial peptides with no influence upon the activity spectrum. Antimicrob Agents Chemother 2009;53(3):1132-41.

[70] Gabriel M, Nazmi K, Veerman EC, Nieuw Amerongen AV, Zentner A. Preparation of LL-37-grafted titanium surfaces with bactericidal activity. Bioconj Chem 2006;17(2):548-50.

[71] Hilpert K, Elliott M, Jenssen H, Kindrachuk J, Fjell CD, Korner J, et al. Screening and characterization of surface-tethered cationic peptides for antimicrobial activity. Chem Biol 2009;16(1):58-69.

[72] Batista MKS, Gallemi M, Adeva A, Gomes CAR, Gomes P. Facile regioselective synthesis of a novel chitosan-pexiganan conjugate with potential interest for the treatment of infected skin lesions. Synthetic Commun 2009;39(7): $1228-40$.

[73] Venter JC. Immobilized and insolubilized drugs, hormones, and neurotransmitters: properties, mechanisms of action and applications. Pharmacol Rev 1982;34(2): 153-87.

[74] Endo Y, Tani T, Kodama M. Antimicrobial activity of tertiary amine covalently bonded to a polystyrene fiber. Appl Environ Microbiol 1987;53(9):2050-5.

[75] Chuang HF, Shukla A, Loose CR, Hammond-Cunningham PT, Stephanopoulos G. Structures including antimicrobial peptides. United States; 2009.

[76] Chen R, Cole N, Willcox MD, Park J, Rasul R, Carter E, et al. Synthesis, characterization and in vitro activity of a surface-attached antimicrobial cationic peptide. Biofouling 2009;25(6):517-24.

[77] Steven MD, Hotchkiss JH. Covalent immobilization of an antimicrobial peptide on poly(ethylene) film. J Appl Polym Sci 2008;110(5):2665-70.

[78] Appendini P, Hotchkiss JH. Surface modification of poly(styrene) by the attachment of an antimicrobial peptide. J Appl Polym Sci 2001;81(3):609-16.

[79] Fields GB, Noble RL. Solid phase peptide synthesis utilizing 9-fluorenylmethoxycarbonyl amino acids. Int J Pept Protein Res 1990;35(3): 161-214.

[80] Rostovtsev VV, Green LG, Fokin VV, Sharpless KB. A stepwise huisgen cycloaddition process: copper(I)-catalyzed regioselective "ligation" of azides and terminal alkynes. Angew Chem Int Ed Engl 2002:41(14):2596-9.

[81] Abad JM, Velez M, Santamaria C, Guisan JM, Matheus PR, Vazquez L, et al Immobilization of peroxidase glycoprotein on gold electrodes modified with mixed epoxy-boronic acid monolayers. J Am Chem Soc 2002;124(43): 12845-53.

[82] Lee MR, Shin I. Fabrication of chemical microarrays by efficient immobilization of hydrazide-linked substances on epoxide-coated glass surfaces. Angew Chem Int Ed Engl 2005;44(19):2881-4.

[83] Hudalla GA, Murphy WL. Immobilization of peptides with distinct biological activities onto stem cell culture substrates using orthogonal chemistries. Langmuir 2010;26(9):6449-56.

[84] Cole N, Hume EB, Vijay AK, Sankaridurg P, Kumar N, Willcox MD. In vivo performance of melimine as an antimicrobial coating for contact lenses in models of CLARE and CLPU. Invest Ophthalmol Vis Sci 2010;51(1):390-5. 